\title{
AVALIAÇÃO DA OCORRÊNCIA DE CONTAMINAÇÃO MICROBIOLÓGICA NO AQÜÍFERO FREÁTICO LOCALIZADO SOB O CEMITÉRIO DA VÁRZEA EM RECIFE-PE
}

\author{
EVALUATION OF THE MICROBIAL CONTAMINATION OCCURRENCE IN THE AQUIFER UNDER \\ VÁRZEA CEMETERY IN RECIFE CITY, BRAZIL
}

\author{
Felipe Rodrigues de Almeida ${ }^{1}$, Jeane Correia Espíndula², \\ Ulrich Vasconcelos ${ }^{1}$ e Glícia Maria Torres Calazans ${ }^{1}$
}

Recebido em: 30/09/2006; aceito em: 15/12/2006

\begin{abstract}
RESUMO Este trabalho avaliou a ocorrência de microrganismos no aqüífero freático localizado sob o Cemitério da Várzea em Recife-PE. No período de janeiro a agosto de 2003 foram realizadas análises em cinco etapas de amostras de águas em poços de oito residências situadas próximas ao cemitério, e de três poços de monitoramento perfurados no interior deste. O número mais provável de coliformes totais e termotolerantes, Pseudomonas aeruginosa, Clostridium perfrigens e bactérias proteolíticas foi estimado pela técnica dos tubos múltiplos. Bactérias heterotróficas foram determinadas pela técnica do Pour Plate. Foi observada a diminuição dos coliformes totais e dos termotolerantes pela presença de Pseudomonas aeruginosa. Os resultados obtidos foram indicativos da contaminação microbiana do aqǘfero pelo necrochorume.
\end{abstract}

Palavras-chave: contaminação de aqüíferos, microrganismos indicadores, cemitérios

\begin{abstract}
Occurrence of microorganisms in the aquifer under Várzea Cemetery located in Recife city (Brazil) was evaluated. From January to August of 2003, samples from well waters of eight wells of residences surrounding the cemetery and three wells of the cemetery field were analyzed. Analysis were divided in five sets. Most Probable Number of coliform bacteria, thermotolerant bacteria, Pseudomonas aeruginosa, Clostridium perfringens and proteolytic bacteria were estimated by using the multiple tubes technique. Heterotrophyc bacteria were counted by using pour-plate technique. It was observed decreasing of coliform populations in presence of Pseudomonas aeruginosa. The results indicated microbial contamination of the aquifer by the leachate.
\end{abstract}

Key-words: aquifer contamination, indicator microorganisms, cemeteries

\section{INTRODUÇÃO}

As águas subterrâneas representam aproximadamente $22 \%$ de toda massa aquática doce no planeta, estimada em 3\%. Com a população aumentada seis vezes e o consumo de água doce no planeta triplicado nos últimos 50 anos, os recursos hídricos disponíveis estão com sua qualidade comprometida e como consequiência, a utilização das águas das reservas subterrâneas vem aumentando (VASCONCELOS et al., 2005).

A maior causa da poluição comumente observada em águas subterrâneas está associada às práticas de saneamento em áreas que não dispõem de rede de esgoto, ao lançamento de efluentes líquidos industriais em corpos de água ou diretamente no solo, às práticas convencionais de cultivo agrícola e mais recentemente à presença de cemitérios (MATOS, 2001).

Com o crescimento do número de cemitérios, as preocupações ambientais também aumentaram. A profundidade das covas, condições do solo, drenagem e proximidades às cidades são há muitos anos, focos de estudos.
Contaminações por metais pesados e substâncias utilizadas nos embalsamamentos já foram descritas como contaminantes de aqüíferos e atenções maiores vêm sendo dadas com respeito a microrganismos nas amostras de água (SPONGBER; BECKS, 2000).

O corpo humano é abrigo de muitos microrganismos dos quais alguns são patógenos. Quando um indivíduo morre, o processo de degradação ocorre por ação de enzimas e pela ação bacteriana, resultando ao final, gases e necrochorume. A infiltração da água da chuva é o principal mecanismo de transporte de substâncias e microrganismos para corpos de água subterrâneos e o primeiro ano de sepultamento do cadáver é considerado do ponto de vista microbiológico, o mais importante (MARINHO, 1998).

Diversos fatores geológicos influenciam o transporte de substâncias e microrganismos por via hídrica no solo (URBAN, 2002). Durante a penetração, a água passa por um processo de filtração onde partículas suspensas são removidas, inclusive microrganismos, porém

\footnotetext{
${ }^{1}$ Universidade Federal de Pernambuco, Centro de Ciências Biológicas, Departamento de Antibióticos (almeidabiomed@yahoo.com.br), (ulvasco@gmail.com), (calazans@ufpe.br)

${ }^{2}$ Universidade Federal de Pernambuco, Centro de Tecnologia e Geociências, Departamento de Engenharia Civil (jjespindula@terra.com.br)
} 
bactérias lipolíticas, clostrídios e Pseudomonas aeruginosa já foram identificados em amostras de água do subsolo (MORGAN, 2004).

Como é de extrema importância manter poços destinados ao abastecimento humano à uma distância suficientemente livre de possíveis fontes de contaminação e uma vez contaminado, o transporte do agente poluidor segue preferencialmente a direção do fluxo das águas do aqüífero, este presente trabalho objetivou identificar alguns tipos de microrganismos que ocorrem no aquífero freático situado abaixo do Cemitério da Várzea e região circunvizinha, localizado na zona oeste da cidade do Recife,
Pernambuco e correlacionar a presença de determinados microrganismos nas amostras de águas de poços à decomposição de cadáveres sepultados nesse cemitério

\section{ÁREA DE ESTUDO}

O Cemitério da Várzea ocupa uma área de $21.700 \mathrm{~m}^{2}$ e está localizado na porção oeste do município do Recife (coordenadas UTM $284.750 \mathrm{mE}$ e $9.110 .140 \mathrm{mN}$ ), ao sul da Avenida Caxangá e contíguo ao campus da Universidade Federal de Pernambuco, distando aproximadamente $800 \mathrm{~m}$ a leste da margem direita do rio Capibaribe (Figura 1).

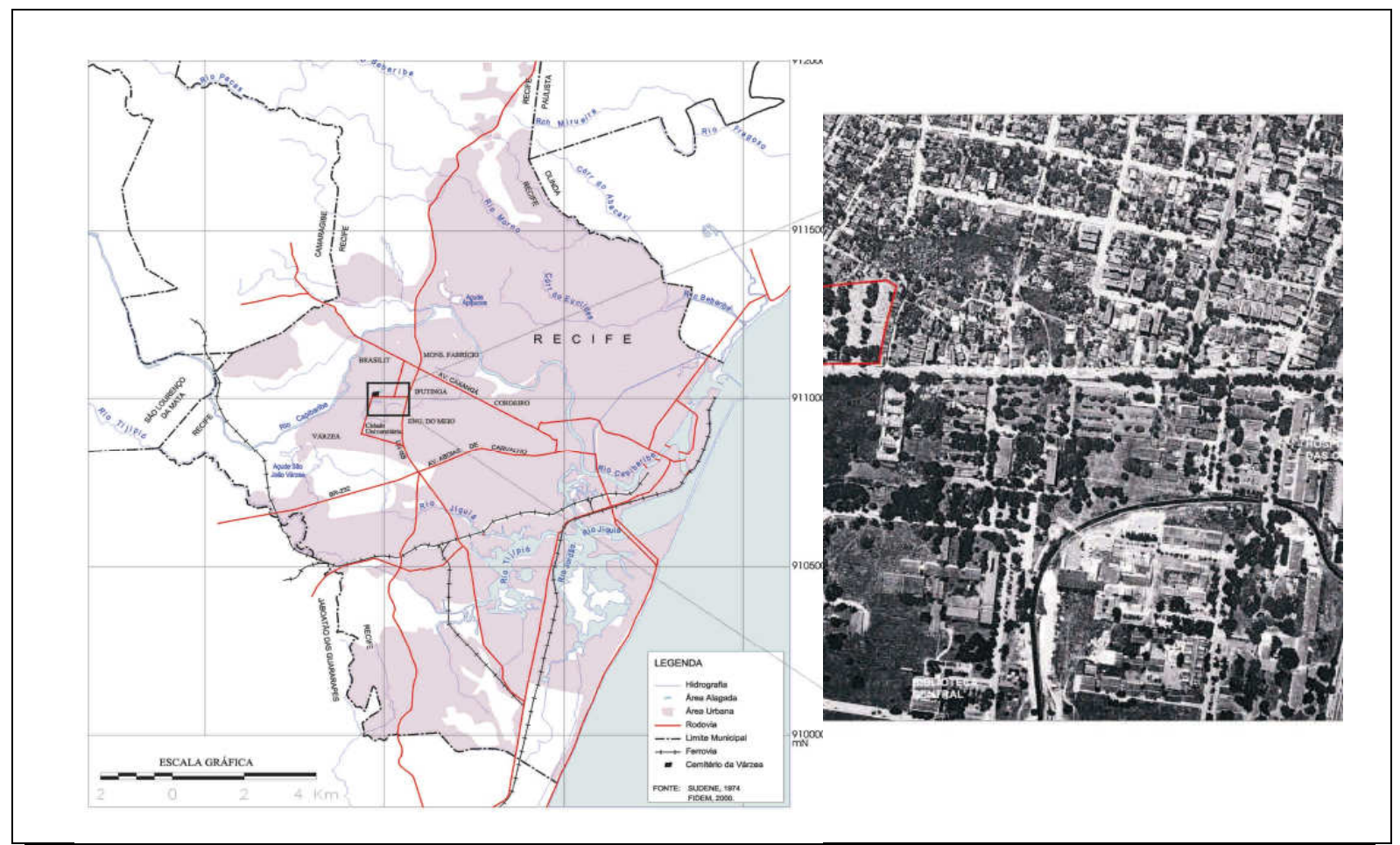

Figura 1- Localização do Cemitério da Várzea

Figure 1- Location of Várzea Cemetery

Internamente é distribuído em dezoito quadras e três blocos de catacumbas, perfazendo um total de 3.519 túmulos (EMLURB, 2003). Nas quadras, embora, predominem as covas rasas, com escavações de 0,6 a $0,8 \mathrm{~m}$ de profundidade. Há também túmulos em blocos pré-moldados, constituídos por dois compartimentos revestidos com placas de alvenaria sem reboco, que alcançam a profundidade de $1,5 \mathrm{~m}$. Nos blocos de catacumba, os túmulos compreendem gavetas revestidas internamente por cimento e, em sua maioria, acima da superfície do terreno. Sua implantação ocorreu em 1953 e em sua maior parte, as sepulturas não são perpétuas, havendo reutilização das mesmas após um período mínimo de dois anos em média anual de 1.516 enterramentos.

A área do estudo situa-se na Planície Costeira do Recife, constituída por sedimentos quaternários, limita-se ao norte e ao sul com as colinas da Formação Barreiras, a oeste com os morros do Embasamento Cristalino e a leste com o Oceano Atlântico. A ação dos rios, sobretudo, o Capibaribe, alterou de maneira significativa a disposição do conteúdo sedimentar da mesma. O interior do cemitério está assentado em terreno constituído por sedimentos clásticos inconsolidados. Até a profundidade de $3 \mathrm{~m}$, variam, granulometricamente, entre areias finas 
com siltes e argilas, de coloração escura nos horizontes mais argilosos, e clara nos mais cascalho de $6 \mathrm{~m}$ a $8 \mathrm{~m}$ de profundidade.

Nas ruas de entorno do cemitério da Várzea, observa-se que a ocupação está constituída, de forma predominante, por residências de baixa renda que apesar de possuírem serviços de fornecimento de energia elétrica, abastecimento de água e coleta de lixo, são desprovidas de esgotamento sanitário.

\section{MATERIAL E MÉTODOS}

\section{Coleta e amostragem}

As amostras de águas foram coletadas em onze poços ao todo: três poços de monitoramento localizados no interior do Cemitério da Várzea (profundidades dos poços: 8,0; 9,5 e 8,5 m, respectivamente) e oito poços em residências localizadas nas redondezas, sendo a mais distante, cerca de $110 \mathrm{~m}$ a sudoeste do muro do cemitério (profundidades dos poços: 12,0; 9,0; 13,$0 ; \quad 13,0 ; \quad 10,0 ; \quad 9,0 ; \quad 9,0$ e $9,0 \mathrm{~m}$, respectivamente). Todas as amostras foram coletadas em frascos com tampa esmerilada com capacidade de $500 \mathrm{ml}$ de duas formas: diretamente do cano ou torneiras ligadas aos poços das residências e para as coletas nos três poços de monitoramento localizados no interior do cemitério foram usados coletores do tipo beiler para então transferir as amostras de águas para os frascos com tampa esmerilhada.

As coletas foram divididas em cinco etapas, entre os meses de janeiro a agosto de 2003, sendo que da terceira a quinta etapas foram coletadas apenas águas dos poços de monitoramento no arenosos, seguidos de sedimentos predominantemente arenosos, com ocorrência de interior do cemitério da Várzea.

\section{Análises bacteriológicas das amostras de água}

As análises bacteriológicas das amostras foram realizadas de acordo com o recomendado pelas normas do Standard Methods for the Examination of Water and wastewater. $\mathrm{O}$ Número Mais Provável por $100 \mathrm{~mL}$ (NMP/100mL) foi estimado utilizando a técnica dos tubos múltiplos em série de dez tubos para coliformes totais, Clostridium perfrigens, Pseudomonas aeruginosa (APHA, AWWA, WEF, 1998). Para bactérias proteolíticas foi utilizada a série de três tubos (APHA, AWWA, WEF, 1971) e na pesquisa de coliformes totais e $P$. aeruginosa, da quinta etapa, o NMP $/ 100 \mathrm{~mL}$ foi estimado utilizando a série de 5 tubos para melhor visualizar as interações entre estes os mesmos.

Os coliformes termotolerantes foram identificados quanto sua presença ou ausência e a contagem de bactérias heterotróficas totais foi estimada utilizando a técnica do Pour plate (APHA, AWWA, WEF, 1998).

\section{RESULTADOS E DISCUSSÃO}

Os resultados obtidos foram confrontados com critérios microbiológicos, de acordo com a Portaria 518/04 do Ministério da Saúde que estabelece os critérios obrigatórios no país para água potável tratada. Como as coletas foram efetuadas em cinco etapas, os resultados estão apresentados nas tabelas de 1 a 5:

Tabela 1- Resultados das análises microbiológicas das amostras de água na primeira etapa de coletas Table 1-Results of the bacteriological water analysis from the first set of sampling

\begin{tabular}{l|c|c|c|c|c|c|c|c|c}
\hline \multirow{2}{*}{ Microrganismos } & \multicolumn{7}{|c}{ Poços } \\
\cline { 2 - 11 } & PM.1 & PR.1 & PR.2 & PR.3 & PR.4 & PR.5 & PR.6 & PR.7 & PR.8 \\
\hline $\begin{array}{l}\text { Coliformes totais } \\
\text { (NMP/100mL) }\end{array}$ & $>23$ & 23 & $<1,1$ & 3,6 & - & $<1,1$ & $>23$ & $>23$ & $>23$ \\
\hline $\begin{array}{l}\text { Coliformes } \\
\text { termotolerantes }\end{array}$ & + & + & - & + & $-*$ & - & + & + & + \\
\hline $\begin{array}{l}\text { Clostridium } \\
\text { perfringens }\end{array}$ & 23 & $>23$ & $>23$ & 6,9 & - & - & $>23$ & $>23$ & $>23$ \\
\hline $\begin{array}{l}\text { Heterotróficos } \\
\text { totais (UFC/mL) }\end{array}$ & $>10^{5}$ & 190 & 180 & 54 & 150 & 38 & 900 & 1400 & 260 \\
\hline $\begin{array}{l}\text { Proteolíticos } \\
\text { (NMP/100mL) }\end{array}$ & $\geq 2400$ & $\geq 2400$ & 23 & 43 & 23 & 460 & 150 & 210 & $\geq 2400$ \\
\hline
\end{tabular}

NMP/100 mL: Número mais provável por 100mL; UFC/mL: Unidades formadoras de colônias por mililitro; P.R.: Poço residencial; P.M.: Poço de monitoramento; + : positivo; -: negativo

$(*)$ Resultados com ensaio presuntivo negativo (não necessária continuidade das análises) 
Os índices de contaminação por coliformes totais, $C$. perfrigens e bactérias proteolíticas nos poços residenciais $1,6,7$ e 8 , foram bastante elevados, equiparando-se com os índices obtidos nas análises feitas no poço de monitoramento 1 (interior do cemitério).

As bactérias heterotróficas mostraram-se em concentrações elevadas nos poços residenciais 6 , 7 e no poço de monitoramento 1 , acima do índice recomendado pela portaria 518/04 para uma água considerada em boas condições de higiene.

Os coliformes termotolerantes se mostraram presentes na análise das águas dos poços residenciais $1,3,6,7,8$ e do poço de monitoramento 1 , indicando contaminação fecal recente. Os poços residenciais 2,4 e 5 apresentaram-se dentro dos padrões exigidos para água potável, porém, o poço residencial 2 apresentou concentração elevada de $C$. perfrigens, indicando uma contaminação fecal remota. A segunda etapa de coletas compreendeu apenas os poços residenciais $2,4,5,7$ e 8 , e dos poços de monitoramento. Os resultados obtidos estão discriminados na tabela 2 .

Tabela 2- Resultados das análises microbiológicas das amostras de água na segunda etapa de coletas Table 2-Results of the bacteriological water analysis from the second set of sampling

\begin{tabular}{l|c|c|c|c|c|c|c|c}
\hline \multirow{2}{*}{ Microrganismos } & \multicolumn{7}{c}{ Poços } \\
\cline { 2 - 9 } & PM.1 & PM.2 & PM.3 & PR.2 & PR.4 & PR.5 & PR.7 & PR.8 \\
\hline $\begin{array}{l}\text { Coliformes totais } \\
\text { (NMP/100mL) }\end{array}$ & $>23$ & 23 & $>23$ & 23 & 2,2 & 1,1 & 2,2 & $>23$ \\
\hline $\begin{array}{l}\text { Coliformes } \\
\text { termotolerantes }\end{array}$ & + & + & + & - & - & - & + & + \\
\hline $\begin{array}{l}\text { Clostridium perfringens } \\
\text { Heterotróficos totais } \\
\text { (UFC/mL) }\end{array}$ & 23 & $>23$ & $>23$ & 912 & 6,9 & 2,2 & $>23$ & $>23$ \\
\hline $\begin{array}{l}\text { Proteolíticos } \\
\text { (NMP/100mL) }\end{array}$ & $\geq 2400$ & $\geq 2400$ & $\geq 2400$ & 1100 & 43 & 93 & 210 & $\geq 2400$ \\
\hline
\end{tabular}

NMP/100 mL: Número mais provável por 100mL; UFC/mL: Unidades formadoras de colônias por mililitro; P.R.: Poço residencial; P.M.: Poço de monitoramento; + : positivo; -: negativo

(*) Resultados com ensaio presuntivo negativo (não necessária continuidade das análises)

As análises realizadas nas amostras de águas dos poços de monitoramento apresentaram índices elevados para todos os microrganismos pesquisados. Os poços residenciais 4 e 5, anteriormente aprovados pelos índices obtidos, tiveram no segundo momento, o aumento do índice para coliformes totais e $C$. perfrigens. $\mathrm{O}$ poço residencial 2 apresentou elevados índices para coliformes totais, $C$. perfrigens, bactérias heterotróficas e bactérias proteolíticas e ausência de coliformes termotolerantes. Os poços residenciais 7 e 8 tiveram suas águas condenadas devido à presença de coliformes totais e termotolerantes. Houve uma queda brusca na concentração de coliformes totais no poço residencial 7 , quando comparados com os valores obtidos na primeira etapa.

Da terceira a quinta etapa, somente as análises de amostras obtidas dos poços de monitoramento foram realizadas com o objetivo de avaliar o papel do cemitério da Várzea na contaminação microbiológica do aqüífero freático e os resultados dessas análises estão apresentadas nas tabelas 3 a 5 :

Tabela 3- Resultados das análises microbiológicas das amostras de água na terceira etapa de coletas envolvendo apenas poços de monitoramento

Table 3-Results of the bacterial water analysis from the third set of sampling involving only the monitoring wells of Várzea cemetery

\begin{tabular}{l|c|c|c}
\hline \multirow{2}{*}{ Microrganismos } & \multicolumn{3}{|c}{ Poços } \\
\cline { 2 - 4 } & PM.1 & PM.2 & PM.3 \\
\hline Coliformes totais (NMP/100mL) & 1,1 & 23 & + \\
\hline Coliformes termotolerantes & - & + & $>23$ \\
\hline Clostridium perfringens & 3,6 & $>23$ & $47 \times 10^{4}$ \\
\hline Heterotróficos totais (UFC/mL) & $5,4 \times 10^{4}$ & $24 \times 10^{4}$ & $\geq 2400$ \\
\hline Proteolíticos (NMP/100mL) & $\geq 2400$ & $\geq 2400$ & ?
\end{tabular}

NMP/100 mL: Número mais provável por $100 \mathrm{~mL}$; UFC/mL: Unidades formadoras de colônias por mililitro; P.M.: Poço de monitoramento; + : positivo; -: negativo 
De acordo com os resultados obtidos, é possível notar que os índices obtidos para coliformes totais e $C$. perfrigens no poço de monitoramento 1 caíram significativamente, além da ausência de coliformes termotolerantes nesta amostra analisada. Os poços de monitoramento 2 e 3 (nas áreas destinadas à sepultamentos recentes) apresentaram elevados índices para coliformes totais, $C$. perfrigens e bactérias heterotróficas, semelhantes aos resultados obtidos na segunda etapa. Já as concentrações de bactérias proteolíticas mantiveram-se igualmente elevadas quando comparadas aos resultados anteriores.

Tabela 4- Resultados das análises microbiológicas das amostras de água na quarta etapa de coletas envolvendo apenas poços de monitoramento

Table 4-Results of the bacterial water analysis from the fourth set of sampling involving only the monitoring wells of Várzea cemetery

\begin{tabular}{|c|c|c|c|}
\hline \multirow{2}{*}{ Microrganismos } & \multicolumn{3}{|c|}{ Poços } \\
\hline & PM.1 & PM.2 & PM.3 \\
\hline Coliformes totais (NMP/100mL) & $<1,1$ & $<1,1$ & 5,1 \\
\hline Coliformes termotolerantes & - & - & - \\
\hline Clostridium perfringens & $>23$ & $>23$ & $>23$ \\
\hline Heterotróficos totais (UFC/mL) & $4,8 \times 10^{4}$ & $11 \times 10^{4}$ & $215 \times 10^{4}$ \\
\hline Proteolíticos (NMP/100mL) & $\geq 2400$ & $\geq 2400$ & $\geq 2400$ \\
\hline
\end{tabular}

NMP/100 mL: Número mais provável por $100 \mathrm{~mL}$; UFC/mL: Unidades formadoras de colônias por mililitro; P.M.: Poços de monitoramento; + : positivo; -: negativo

Por coincidir ao período mais chuvoso, provavelmente foram obtidas amostras mais diluídas e a partir da análise dos resultados da quarta etapa foi possível constatar que os índices de coliformes totais nas análises realizadas nos poços de monitoramento 1,2 e 3 caíram significativamente, sendo observado ausência de coliformes termotolerantes nas amostras dos três poços. Apenas os índices de $C$. perfrigens e bactérias proteolíticas mantiveram-se elevados e a determinação de clostrídios foi abonada por se manter semelhante o período. Desta forma, confirmando as observações feitas por Morgan (2004) com relação à população de clostrídios em amostras de águas sob cemitérios.
Durante a quarta fase também foi levantado questionamento sobre a diminuição do número de coliformes. A formação de uma pigmentação azul-esverdeada nos tubos presuntivos do ensaio para coliformes totais chamou a atenção, desencadeando investigação sobre a presença de bactérias antagonistas ao grupo coliforme. Esta poderia ser uma possível explicação para o não aparecimento dessas bactérias em ambiente sabidamente contaminado pelas mesmas. Baseado no conhecimento do fenômeno de antagonismo entre bactérias do grupo coliforme e $P$. aeruginosa (GUILERME; SILVA, 2000), a pesquisa da mesma foi incluída na etapa seguinte.

Tabela 5- Resultados das análises microbiológicas das amostras de água na quinta etapa de coletas envolvendo apenas poços de monitoramento

Table 5-Results of the bacterial water analysis from the fifth set of sampling including only the monitoring wells of Várzea cemetery

\begin{tabular}{|c|c|c|c|}
\hline \multirow{2}{*}{ Microrganismos } & \multicolumn{3}{|c|}{ Poços } \\
\hline & PM.1 & PM.2 & PM.3 \\
\hline Coliformes totais (NMP/100mL) & - & $<2$ & $<2$ \\
\hline Coliformes termotolerantes & _* & - & _- \\
\hline Pseudomonas aeruginosa & $\geq 1600$ & $\geq 1600$ & $\geq 1600$ \\
\hline Heterotróficos totais (UFC/mL) & $9,1 \times 10^{4}$ & $8,9 \times 10^{4}$ & $10 \times 10^{4}$ \\
\hline Proteolíticos (NMP/100mL) & $\geq 2400$ & $\geq 2400$ & $\geq 2400$ \\
\hline
\end{tabular}

NMP/100 mL: Número mais provável por $100 \mathrm{~mL}$; UFC/mL: Unidades formadoras de colônias por mililitro;

P.M.: Poço de monitoramento; + : positivo; -: negativo

(*) Resultados com ensaio presuntivo negativo (não necessária continuidade das análises) 
A coincidência com o período de chuvas, o aumento do nível do aqüífero, a oferta de matéria orgânica abundante, o transporte de nutrientes pelo percolato e a versatilidade nutricional da bactéria $P$. aeruginosa em relação ao grupo coliforme, provavelmente explicam o aumento do número de $P$. aeruginosa e ausência de bactérias do grupo coliforme.

Pode-se observar também que a concentração de bactérias heterotróficas apresentou considerável diminuição quando comparada aos resultados obtidos nas etapas anteriores. Os índices para coliformes totais nos três poços apresentaram redução significativa e coliformes termotolerantes permaneceram ausentes enquanto $P$. aeruginosa mostrou-se elevado. Sendo $P$. aeruginosa uma bactéria extremamente versátil e freqüentemente isolada de poços (VASCONCELOS et al., 2005), sua presença nas águas dos poços de monitoramento certamente se dá por serem os corpos cadavéricos, importantes fornecedores de matéria orgânica e sais, que proporcionam condições favoráveis ao crescimento abundante das mesmas, aumentando a competição nutricional contra bactérias do grupo coliforme que tiveram seu número reduzido e de acordo com o que foi flagrado através da técnica empregada neste trabalho.

Observações feitas por outros autores (PACHECO, 1986; MATOS, 1998; MORGAN, 2004) concluíram que os índices de contaminação dos poços variaram de acordo com sua localização. Neste estudo, tal fato não foi observado porque durante o período das análises, amostras do poço de monitoramento 1 apresentaram altos índices apesar do mesmo está localizado no setor onde os sepultamentos estavam suspensos por mais de um ano. Por outro lado, os poços de monitoramento 2 e 3 apresentaram altos índices já esperados por estarem localizados onde a prática de sepultamentos continua ativa. Por serem as sepulturas com menos de um ano, consideradas de maior risco de contaminação, do ponto de vista microbiológico, os perfis de contaminação apresentados pelos poços de monitoramento ao longo das análises realizadas, correspondem ao observado por Pacheco (1986), Martins et al. (1991), Marinho (1998), Matos (2001) e Morgan (2004).

Era esperado que os poços residenciais mais próximos ao cemitério apresentassem os maiores índices de contaminação, e os mais distantes, menores índices, porém, tal suposição não foi confirmada. Esta observação sugere que não apenas o cemitério pode estar contribuindo para tal contaminação do aqüífero, mas, outros fatores devem ser considerados como esgoto sanitário, estado de limpeza e conservação dos poços, tipo de aqüífero, pluviosidade, entre outros, na contaminação fecal das águas coletadas.

\section{CONCLUSÕES}

As análises bacteriológicas das águas dos oito poços demonstraram a presença, principalmente de bactérias heterotróficas e proteolíticas, indicando que a contaminação das águas subterrâneas do aqüífero sob o cemitério da Várzea é gerada pela presença abundante de matéria orgânica e bactérias que dominam durante o processo de decomposição. As bactérias do grupo coliforme apresentaram variações bruscas de seus índices, chegando até a sua ausência e os altos índices de $P$. aeruginosa reforçam a suspeita de inibição dos coliformes por essa bactéria. A existência de tal antagonismo entre esses grupos poderá mascarar dessa forma, resultados de análises. Os resultados aqui obtidos não puderam por si só, caracterizar o cemitério como única fonte poluidora do aqüífero, por conta da falta de saneamento básico existente nas residências localizadas no seu entorno. No entanto, os resultados alertam para a necessidade de se promover investigações sistemáticas nos aquíferos freáticos localizados em áreas de cemitérios, principalmente em áreas residenciais onde se costuma realizar exploração de água através de poços. 


\section{REFERÊNCIAS}

APHA (American Public Health Association) Standard Methods for the Examination of Water and Wastewater. Washington: APHA, AWWA, WEF, 1971.

APHA (American Public Health Association) Standard Methods for the Examination of Water and Wastewater. Washington: APHA, AWWA, WEF,1998.

BRASIL. Ministério da Saúde. Portaria n 518 de 25 de março de 2004. Estabelece normas e o padrão de potabilidade da água destinada ao consumo humano. Diário Oficial da República Federativa do Brasil, Brasília, 26 mar 2004.

EMLURB, Empresa de Manutenção e Limpeza Urbana. Informações sobre o cemitério da Várzea Recife/PE. Recife: EMLURB, 2003.

Guilherme, E.F.M.; Silva, J.A.M. Pseudomonas aeruginosa como indicador de contaminação hídrica, Revista Higiene Alimentar. São Paulo, v. 14, n.76, p.43-47, 2000.

Marinho, A.M.C.P. Contaminação de aqüíferos por instalação de cemitérios. Estudo de caso do Cemitério São João Batista, Fortaleza - CE. 1998. 88f. Dissertação (Mestrado em Geologia) - Departamento de Geologia, UFC, 1998.

Martins, M.T; Pellezari, V.H; Pacheco, A; Myaki, P.M; Adams, C; Bossolan, N.R.S; Mendes, J.M.B; Hassuda, S. Qualidade bacteriológica de águas subterrâneas em cemitérios. Revista de Saúde Pública. São Paulo, v. 25, n. 1, p. 47-52, 1991.
Matos, B.A. Avaliação da ocorrência e do transporte de microrganismos no aquífero freático do Cemitério de Vila Nova Cachoeirinha, município de São Paulo. 2001. 161f. Tese (Doutorado em Recursos Minerais e Hidrogeologia) Instituto de Geociências - USP, 1998.

Morgan, O. Infectious disease risks from dead bodies following natural disasters. Pan American Journal of Public Health, Washington (DC) v. 15, n.5, p. 307312, 2004.

Pacheco, A. Os cemitérios como risco potencial para as águas de abastecimento. Revista do Sistema de Planejamento e da Administração Metropolitana, n. 17, p.25-31, 1986.

Spongberg, A.L; Becks, P.M. Inorganic soil contamination from cemetery leachate. Water, Air and Soil Pollution. v. 117, n.1-4, p. 313-327, 2000.

Urban, R. Can earth funeral cause environmental pollution, soil contamination and health endangerment? Wasser und Boden. Boppard, v. 54, n. 11, p. 25-30, 2002.

Vasconcelos, U; Andrade Lima, M.A.G; Medeiros, L.V; Calazans, G.M.T. Evidência do antagonismo entre Pseudomonas aeruginosa sobre bactérias indicadoras de contaminação fecal da água. Revista Higiene Alimentar, São Paulo, v. 20, n. 140, p. 127131, 2006. 
Avaliação da ocorrência de contaminação microbiológica no aqüífero freático localizado sob o cemitério da Várzea em Recife-PE 